\title{
Psychological changes during a controlled trial of rehabilitation in chronic respiratory disability
}

\author{
A COCKCROFT, G BERRY, EB BROWN, C EXALL \\ From the Medical Research Council Pneumoconiosis Unit, Llandough Hospital, Penarth, South Wales
}

ABSTRACT Thirty-four men with chronic respiratory disability took part in a randomised, controlled trial of physical training. The contrul group also undertook exercise training after their control period. During the study measurements were made of exercise tolerance (12-minute walking distance) and the men completed two psychology questionnaires. Walking distance improved significantly more in the treatment group than in the control group. Both groups recorded scores suggesting psychological "improvement" and the changes in the two groups were not significantly different from each other. There were no consistent associations between the increase in walking distance and changes in psychological scores. Initial psychological scores were not useful in predicting changes in walking distance. The results suggest that the effect of treatment on walking distance was not psychological.

Several controlled studies have found improvement in exercise tolerance in people with chronic respiratory disability after exercise training. ${ }^{12}$ The mechanism of the improvement remains in some doubt and there is a possibility that psychological factors are important. Patients certainly report increased general wellbeing after the rehabilitation; but whether this is cause or effect (if either) of the increased exercise tolerance is not clear.

To investigate psychological effects men taking part in a controlled trial of rehabilitation were asked to complete questionnaires before and during the study period. The main results of the trial have already been reported. ${ }^{3}$

\section{Methods}

Thirty-nine men entered the study. Most of them were ex-coalworkers with coalworker's pneumoconiosis as well as chronic obstructive airways disease, and all were breathless on exertion. Men were excluded from entry if they were over 70 years old, had another disabling condition, or required domiciliary oxygen. Entrance was sequential over about three months and all men were told at the outset that we thought that exercises could help them and that they would go to a rehabilitation centre either immediately or after a few months.

Address for reprint requests: Dr A Cockcroft, Department of Medicine, Charing Cross Hospital, Fulham Palace Road, London W6 8RF.
After entry each man was allocated to the treatment or control group. Allocation was initially random; later a method known as minimisation was used to ensure an even spread of certain variables between the groups. ${ }^{4}$ Smoking habits, age, and 12-minute walking distance were the variables chosen. The treatment group spent six weeks of progressive exercise training in a rehabilitation centre and continued with exercises at home afterwards. The men in the control group were not advised to exercise initially but after four months they also went to the rehabilitation centre.

Both groups of men were assessed at entry, at two months, at four months, and at eight to nine months (when the controls had also had exercise training). Assessments included spirometry, a 12-minute walking test, ${ }^{5}$ and a treadmill exercise test. The men completed two psychological questionnaires at each assessment. Someone who was unaware of the study groups was on hand to help if necessary but in general the questionnaires were self-administered.

The first questionnaire was the standard LorrMcNair Mood Questionnaire. ${ }^{6}$ It consists of a series of adjectives that the subject qualifies by "not at all," "quite a bit," or "extremely." The adjectives fall into six groups, giving scores for tension/anxiety (A), depression/dejection (B), anger/hostility (C), fatigue/inertia (D), confusion (E), and vigour/ activity (F). The other questionnaire was designed for the study and consisted of a series of gradedresponse questions on relevant topics. In each ques- 
tion two opposite statements, such as "I never feel breathless" and "I feel breathless all the time," are joined by a $10-\mathrm{cm}$ line and the subject marks the line at a point to indicate where he lies between the two extremes. The scores for the graded-response questions were analysed after an arc-sin transformation to produce a more normal distribution of the scores. ${ }^{7}$ There were 20 questions falling into three sections, in each of which the individual scores were combined. The validity of this grouping of the questions was later confirmed by the use of cluster analysis of the scores for the individual questions to see which were more closely associated with each other. ${ }^{8}$ At the end of the study each subject completed an Eysenck Personality Questionnaire, thought to reflect relatively fixed personality traits.

The effects of treatment were assessed by comparing the mean change of a variable in the treatment group with the mean change in the control group after the effects of smoking habits, age, and initial walking distance, the variables used for matching in the study design, had been taken into account by means of covariance analysis.

\section{Results}

Thirty-four men completed the controlled study, 18 in the treatment group and 16 controls. After two months the treated men had improved their walking distance significantly more than the control group, although both groups had improved. The treatment group maintained most of the improvement during the rest of the study period and the controls continued a gradual improvement, more noticeable after their rehabilitation period. These results have been reported previously. ${ }^{3}$

There were no important differences between the psychology scores recorded by the two groups at the beginning of the study or between their scores on the Eysenck Personality Questionnaires (table 1). During the study period both groups recorded scores suggesting psychological "improvement" in that they had reductions in the Lorr-McNair scores for tension, depression, anger, and fatigue and increases for vigour. The confusion score changed little. The graded-response scores showed improvement in group 1 questions about physical health but little change in group 2 (optimism) or group 3 (socialising), which contained only a few questions. The changes between the first and second assessments are shown in table 2 . There were no significant differences $(p>0.05)$ between the treatment and control group psychology score changes between the first and second assessments or at any point during the rest of the study period.

For most scores changes in the treatment group were paralleled by changes in the control group Figure 1 shows the changes in mean Lorr-McNair score for tension in the two groups during the study. For both groups there was an initial reduction (be-

Table 1 Twelve-minute walking distance (12MD) and psychology scores at the first assessment, and Eysenck Personality Questionnaire (EPQ) scores

\begin{tabular}{|c|c|c|}
\hline & $\begin{array}{l}\text { Treatment group } \\
\text { Mean values } \\
( \pm S D)\end{array}$ & $\begin{array}{l}\text { Control group } \\
\text { Mean values } \\
( \pm S D)\end{array}$ \\
\hline $12 \mathrm{MD}(\mathrm{m})$ & $523( \pm 296)$ & $564( \pm 221)$ \\
\hline $\begin{array}{l}\text { Lorr-McNair scores (range) } \\
\text { A-Tension/anxiety }(0-27) \\
\text { B-Depression/dejection }(0-45) \\
\text { C-Anger/hostility }(0-36) \\
\text { D-Fatigue/inertia }(0-21) \\
\text { E-Confusion }(0-21) \\
\text { F-Vigour/activity }(0-24)\end{array}$ & $\begin{array}{l}\begin{array}{l}8.7 \\
5.6\end{array} \quad( \pm 3.0) \\
5.5 \\
9.6 \quad \pm 4.5 \\
\begin{array}{l}4.9 \\
8.4\end{array} \quad( \pm 2.6) \\
8.43\end{array}$ & $\begin{array}{ll}9 \cdot 1 & ( \pm 5 \cdot 1) \\
7.4 & ( \pm 5.9 \\
6.7 & \pm 4.9 \\
8 \cdot 1 & ( \pm 4 \cdot 3 \\
7.4 & ( \pm 4.7 \\
7.8 & ( \pm 3.0)\end{array}$ \\
\hline $\begin{array}{l}\text { Graded-response scores } \\
\text { Section 1-Physical health } \\
\text { Section 2-Optimism } \\
\text { Section 3-Socialising }\end{array}$ & $\begin{array}{l}0.99( \pm 0.22) \\
0.63( \pm 0.26) \\
0.44( \pm 0.21)\end{array}$ & $\begin{array}{l}0.90( \pm 0.26) \\
0.58( \pm 0.16) \\
0.54( \pm 0.22)\end{array}$ \\
\hline $\begin{array}{l}\text { EPQ scores } \\
\text { Extroversion } \\
\text { Neuroticism } \\
\text { Psychotism } \\
\text { Lie Scale }\end{array}$ & $\begin{array}{rr}2 \cdot 5 & ( \pm 2 \cdot 0) \\
12 \cdot 3 & ( \pm 5 \cdot 0) \\
11 \cdot 8 & ( \pm 6 \cdot 3) \\
13 \cdot 3 & ( \pm 4 \cdot 4)\end{array}$ & $\begin{array}{rr}3.1 & ( \pm 2.6) \\
11.9 & ( \pm 4.4) \\
10.7 & ( \pm 5 \cdot 1) \\
11.9 & ( \pm 5 \cdot 0)\end{array}$ \\
\hline
\end{tabular}

The means for the $12 \mathrm{MD}$ and EPQ are for 18 treated and 16 controls. The means for the other questionnaires are for 17 treated and 14 controls. The graded response scores are given after the arc-sin transformation.

Table 2 Changes in 12-minute walking distance (12MD) and psychology scores between first and second assessments

\begin{tabular}{|c|c|c|c|}
\hline & $\begin{array}{l}\text { Treatment group } \\
\text { Mean change } \\
( \pm S D)\end{array}$ & $\begin{array}{l}\text { Control group } \\
\text { Mean change } \\
( \pm S D)\end{array}$ & $\begin{array}{l}\text { Treatment effect } \\
( \pm S E)\end{array}$ \\
\hline 12MD & $120( \pm 119)$ & $43( \pm 111)$ & $77( \pm 33)$ \\
\hline $\begin{array}{l}\text { A } \\
\text { B } \\
\text { C } \\
\text { D } \\
\text { E } \\
\text { F }\end{array}$ & 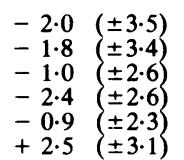 & $\begin{array}{rr}-1.1 & ( \pm 3.8) \\
-2.8 & ( \pm 5.1) \\
-3.2 & ( \pm 5.1 \\
-0.9 & ( \pm 3.4 \\
0 & 0 \\
+0.3 & ( \pm 2.7 \\
03.9)\end{array}$ & $\begin{array}{rr}-1.3 & ( \pm 1.4) \\
+0.8 & ( \pm 1.5 \\
+1.9 \\
-1.5 \\
-0.9 \\
+2.9\end{array} \quad( \pm 1.5)$ \\
\hline
\end{tabular}

Graded-

response scores

Section $1-0.17( \pm 0.24)-0.08( \pm 0.21)-0.09( \pm 0.09)$

Section 2- $-0.06( \pm 0.19)+0.01( \pm 0.16-0.09( \pm 0.07$

Section $3+0.07( \pm 0.15)-0.05( \pm 0.18)+0.11( \pm 0.07)$

The mean change for a variable ireach group was the value at the second assessment minus the value at the first assessment. The treatment effect was significant $(p<0.05)$ for the 12 -minute walking distance but not for any of the psychology scores. For the psychology scores the treatment effect given does not exactly equal the treatment group mean change minus the control group mean change. This is because the five subjects not completing questionnaires at both assessments left the groups slightly unbalanced with regard to the variables taken into account in analysing the differences between them (that is, age, initial 12-minute walking distance, and smoking). 
tween the first and second assessments) followed by a slow increase towards the starting score. In particular, there was no second decrease in the control group after their rehabilitation at the end of their control period. The changes in the Lorr-McNair vigour score (fig 2) suggested the possibility of a treatment effect, the treatment group improving more than the controls initially and then the controls showing further improvement after their rehabilitation. The pattern is similar to that of the 12MD changes (also shown in fig 2). Nevertheless, none of the differences in psychology scores between the groups was significant at the $5 \%$ level.

The results were examined for association between psychology score changes and walking distance changes within each group. In the treatment group increase in walking distance between first and second assessments was significantly associated with decrease in tension score $(p<0.05)$ and decrease in anger score $(p<0.05)$. In the original control group increase in walking distance between first and fourth assessments (the latter after rehabilitation) was significantly associated with decrease in fatigue score $(p<0.05)$. In neither group was increase in walking distance associated with increase in vigour score.

None of the psychology scores at the initial assessment was significantly related to subsequent changes in walking distance during the study period, nor did any of the scores on the Eysenck Personality Questionnaire relate to changes in walking distance during the study.

\section{Discussion}

Our results support the view that taking part in a study that gives increased interest from others and the possibility of physical improvement produces a psychological improvement. In an uncontrolled study the effects of this cannot be separated from a true treatment effect. In our controlled study we found that the psychological improvement in the control group was similar to that in the treatment group, yet there was a significantly greater increase in walking distance in the treatment group. The Lorr-McNair vigour score seemed to improve more in the treatment group initially but did not correlate with increase in walking distance within that group; an increased feeling of vigour therefore seems unlikely to have been responsible for their increased walking distance.

In general, the correlation between changes in psychology score and in walking distance was poor. The changes in scores associated with improved walking distance after rehabilitation in the treatment group (tension and anger scores) were not the

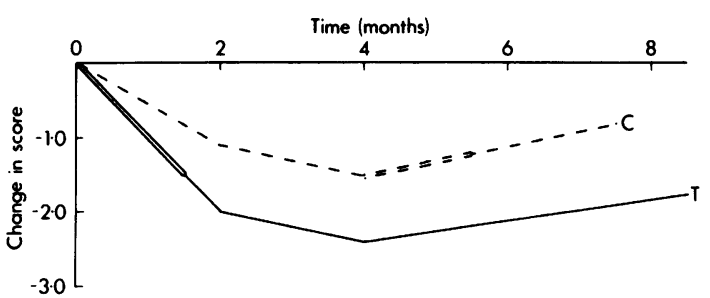

Fig 1 Changes in Lorr-McNair "tension" score during the study. The solid line represents the treatment group and the dashed line the control group. Periods of rehabilitation are shown by double lines.

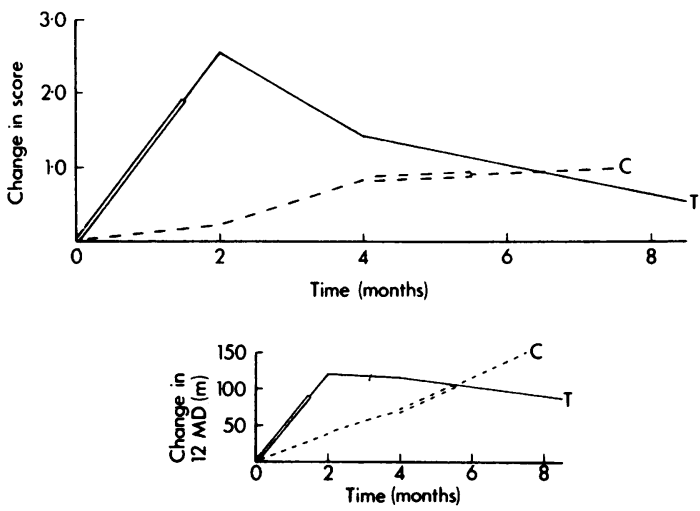

Fig 2 Changes in Lorr-McNair "vigour" score during the study. Treatment and control groups and rehabilitation are represented as in figure 1 . The changes in 12-minute walking distance during the study are shown for comparison. Note the rather similar pattern of changes.

same as the change in score associated with improved walking in the control group (fatigue score). The poor correlation suggests that different factors are responsible for psychological changes and improvement in walking distance.

When the effect of treatment on walking distance between the first and second assessments was reanalysed with the initial psychology scores taken into account, it remained significant at the $5 \%$ level. When it was reanalysed, with the changes in psychology scores between first and second assessments taken into account, it was significant only at around the $10 \%$ level. This type of analysis, however, meant a loss of power because only 29 of the 34 subjects completed the psychology questionnaires at both assessments. Thus the treatment effect still remains even after we have allowed for the psychological changes, which were themselves not significantly different between the groups.

It has been suggested that people with chronic respiratory disability display some psychological abnormalities. ${ }^{10}$ We have no group without respirat- 
ory disability with which to compare the men in our study, but their scores for tension and depression were much lower than those of a group of outpatients being treated for anxiety. ${ }^{1}$ The men in our group were to some extent self-selected and motivated in that they agreed to take part in a study that meant considerable inconvenience and hard work for them. They may not be typical of people with chronic respiratory disability.

We believe that there is now substantial evidence to show that physical rehabilitation can improve exercise tolerance in people with chronic respiratory disability and the present study indicates that this effect is not solely psychological.

We are grateful to Dr David Griffiths for help and advice in the design and interpretation of the questionnaires; to the staff of the Talygarn Rehabilitation Centre, near Llantrisant; and to the men who willingly undertook the training programme and completed the questionnaires.

\section{References}

' McGavin CR, Gupta SP, Lloyd EL, McHardy GJR. Physical rehabilitation for the chronic bronchitic: results of a controlled trial of exercises in the home. Thorax 1977;32:307-11.

${ }^{2}$ Sergysels R, DeCoster A, Degre S, Denolin H. Functional evaluation of a physical rehabilitation program including breathing exercises and bicycle training in chronic obstructive lung disease. Respiration 1979;38:105-11.

${ }^{3}$ Cockcroft AE, Saunders MJ, Berry G. Randomised controlled trial of rehabilitation in chronic respiratory disability. Thorax 1981;36:200-3.

4 White SJ, Freedman LS. Allocation of patients to treatment groups in a controlled clinical study. $B r \quad J$ Cancer 1978;37:849-57.

${ }^{5}$ McGavin CR, Gupta SP, McHardy GJR. Twelve-minute walking test for assessing disability in chronic bronchitis. $\mathrm{Br}$ Med $J$ 1976;1:822-3.

- McNair DM, Lorr M. An analysis of mood in neurotics. $J$ Abnorm Soc Psychol 1964;69:620-7.

${ }^{7}$ Aitken RCB. Measurement of feelings using visual analogue scales. Proc $R$ Soc Med 1969;62:989-93.

${ }^{8}$ Sneath PH, Sokal RR. Numerical taxonomy. San Francisco: Freeman, 1973.

' Eysenck HJ, Eysenck SBG. Manual of the Eysenck Personality Questionnaire. London: Hodder and Stoughton, 1975.

${ }^{10}$ DeCencio DV, Leshner M, Leshner B. Personality characteristics of patients with chronic obstructive pulmonary emphysema. Arch Phys Med Rehab 1968;49:471-5.

" Lorr M, McNair DM. Correlates of length of psychotherapy. $J$ Clin Psychol 1964;20:497-504. 